\title{
Pengaruh Metode Ceramah Terhadap Tingkat Pengetahuan Konsumsi Buah dan Sayur Siswa Sd Negeri 060841 Medan
}

\author{
Abdul Wahab ${ }^{1 *}$, Rizuan ${ }^{2}$ \\ ${ }^{1}$ Universitas Prima Indonesia Kampus 2 J1. Sekip Simpang Sei Kambing Medan \\ 20113, Indonesia \\ Email : awahab.fkm@unprimdn.ac.id
}

\begin{abstract}
ABSTRAK
Kurangnya pengetahuan tentang gizi akan menyebabkan seseorang salah memilih makanan sehingga akan menurunkan konsumsi makan sehat dan berdampak negatif pada status gizi. Rendahnya pengetahuan konsumsi buah dan sayur terjadi di beberapa sekolah dasar di Indonesia. Salah satu metode yang dapat meningkatkan pengetahuan ialah metode ceramah. Jenis penelitian Quasi Eksperimen, rancangan One Group Pretest-Postest Design. Tujuan penelitian menguji pengaruh metode ceramah terhadap tingkat pengetahuan siswa Sekolah Dasar Negeri 060841 Medan tentang konsumsi buah dan sayur. Jumlah sampel 100 siswa terdiri dari kelas IV, V, dan VI. Pengetahuan di ukur dua kali, pre-test dan post-test. Hasil penelitian menunjukan pengetahuan siswa sebelum perlakuan yang berpengetahuan kurang (31\%), cukup (45\%), dan baik (24\%). Setelah perlakuan pengetahuan kurang (21\%), cukup $(46 \%)$, dan baik (33\%). Hasil uji wilcoxon signed rank test menunjukan nilai p-value $=0,107$. Kesimpulan tidak ada pengaruh metode ceramah terhadap tingkat pengetahuan siswa. Saran kepada pihak sekolah agar memberi pendidikan kepada siswa tentang manfaat konsumsi buah dan sayur di dalam kegiatan ekstrakulikuler, saran kepada peneliti yang lain perlu penambahan alat peraga dalam penelitian menggunakan metode ceramah.
\end{abstract}

Kata kunci: Pengetahuan, Metode Ceramah, Siswa Sekolah Dasar, Konsumsi Buah dan Sayur 


\section{Pendahuluan}

Kurangnya pengetahuan tentang gizi, menyebabkan seseorang salah memilih makanan sehingga dapat menurunkan konsumsi makanan sehat dan dapat berdampak negatif terhadap status gizi. Rendahnya pengetahuan konsumsi buah dan sayur terjadi pada siswa sekolah dasar di berbagai wilayah di Indonesia seperti di SD Negeri Babakan Bandung (Lathipuddin, 2018), Kandang Tepus Jawa Timur (Azadirachta, 2017), Kab. Malang (Putri, 2017), Semarang (Putra, 2016), serta di Depok Jawa Barat (Fibrihirzani, 2012).

Rendahnya pengetahuan gizi siswa, khususnya pengetahuan tentang konsumsi sayur dan buah disebabkan berbagai faktor, antara lain karena siswa kurang mendapat informasi atau kurang terpapar informasi mengenai gizi serta konsumsi buah dan sayur. Hal ini didukung penelitian Lestari (2012) yang menyebutkan rendahnya pengetahuan buah dan sayur mengakibatkan konsumsi buah dan sayur menjadi kurang, serta menurut Susantya (2012) yang menyatakan pengetahuan rendah memiliki kemungkinan lebih besar untuk tidak mengonsumsi buah dan sayur.

Salah satu metode untuk menyampaikan pesan menurut ialah metode ceramah karena metode ini mengajar dengan menyampaikan informasi dan pengetahuan secara lisan kepada sejumlah siswa yang pada umumnya mengikuti secara pasif. Hal ini didukung penelitian Sibagariang (2016) yang menemukan ada pengaruh metode ceramah terhadap peningkatan pengetahuan siswa sekolah dasar, dan Rahayu (2016) membuktikan metode ceramah dapat meningkatkan pengetahuan konsumsi buah dan sayur siswa sekolah dasar.

Berdasarkan masalah status gizi yang ditemukan pada siswa SD Negeri 060841 Medan, maka peneliti tertarik melakukan penelitian tentang pengaruh metode ceramah terhadap tingkat pengetahuan konsumsi buah dan sayur yang bertujuan untuk mengukur tingkat pengetahuan sebelum dan sesudah perlakuan, serta untuk menguji pengaruh metode ceramah terhadap tingkat pengetahuan siswa.

\section{Metode Penelitian}

Jenis penelitian Quasi Eksperimen dengan rancangan One Group Pretest-Postest Design, perlakuan berupa metode ceramah yang dilakukan mahasiswa FKM Unpri Medan peminatan gizi menggunakan alat bantu infocus yang dilakukan selama 3 hari Lokasi penelitian di SD Negeri 060841 yang berada di lingkungan kampus Universitas Prima Indonesia, sengaja dipilih-karena berdasarkan hasil pengukuran status gizi secara antropometri dengan indeks berat badan menurut tinggi badan yang dilakukan mahasiswa peminatan gizi FKM UNPRI Tahun 2019, ditemukan 1 siswa (4\%) berstatus gizi kurus, 2 siswa (8\%) berstatus gizi gemuk, 4 siswa (16\%) berstatus obesitas, selebihnya 18 siswa $(72 \%)$ berstatus gizi normal. Pemilihan lokasi sekaligus sebagai bentuk kepedulian terhadap lingkungan kampus.

Populasi seluruh siswa SD Negeri 060841 yang berjumlah 270 orang, sampel dipilih secara sengaja (Pupossive Sampling) dengan mempertimbangkan kemudahan komunikasi, yakni kelas 4,5 dan 6 yang berjumlah 100 orang. Pengumpulan data menggunakan kuesioner yang diisi langsung oleh sampel sebelum dan sesudah perlakuan. Pengolahan data dilakukan menggunakan program SPSS dan analisis data secara Deskriptif dengan menyajikan data hasil olahan kebentuk tabel agar mudah dibaca, serta uji yang digunakan Wilcoxon signed rank test.

\section{Hasil dan Pembahasan}

Sekolah Dasar Negeri 060841 Medan, berlokasi di Jl. Damar No.5A Kelurahan Sekip, Kecamatan Medan Petisah, Kota Medan, Sumatera Utara. Menurut Data Pokok Pendidikan (Dapodik) Tahun 2018-2019, SDN 060841 yang terakreditasi B berstatus milik pemerintah daerah, dengan SK Pendirian Nomor XX/1974 dan SK izin operasional berdasarkan Perwal Kota Medan Nomor 20 Tahun 2018 Tanggal 14 Februari 2018. Jumlah guru 17 orang (2 
orang laki-laki, 15 orang perempuan), 15 orang bertatus PNS dan 2 orang Guru Honorer, yang seluruhnya sarjana. Jumlah siswa 270 orang (laki-laki 143 orang, perempuan 127 orang) yang tersebar pada enam ruang kelas.

\section{Jumlah Sampel Berdasarkan Kelas, Jenis Kelamin dan Umur}

Berdasarkan tabel 1, seluruh siswa di kelas 4 yang berjenis kelamin laki-laki 17 orang (19\%), perempuan 14 orang (16\%), dengan umur 8 tahun (7 orang), umur 9 tahun (21 orang), umur 10 tahun (3 orang), serta siswa di kelas 5 yang berjenis kelamin laki-laki 17 orang (19\%), perempuan 9 orang (10\%), dengan umur 9 tahun (3 orang), umur 10 tahun (18 orang), umur 11 tahun (4 orang), umur 12 tahun ( 1 orang), sedangkan di kelas 6 jumlah siswa yang berjenis kelamin laki-laki 18 orang (20\%), perempuan 14 orang (16\%), dengan umur 10 tahun (5 orang), 11 tahun (19 orang), umur 12 tahun (8 orang), sebagaimana disajikan di Tabel 1.

Tabel 1. Distribusi Sampel Berdasarkan Kelas, Jenis Kelamin dan Umur

\begin{tabular}{|c|c|c|c|c|c|c|c|c|c|c|c|c|c|}
\hline \multirow[t]{2}{*}{ Kelas } & \multirow[t]{2}{*}{$\begin{array}{c}\text { Jenis } \\
\text { Kelamin }\end{array}$} & \multicolumn{2}{|c|}{8 tahun } & \multicolumn{2}{|c|}{9 tahun } & \multicolumn{2}{|c|}{10 tahun } & \multicolumn{2}{|c|}{11 tahun } & \multicolumn{2}{|c|}{$\begin{array}{c}12 \\
\text { tahun }\end{array}$} & \multicolumn{2}{|c|}{ Jumlah } \\
\hline & & $\mathbf{n}$ & $\%$ & $\mathbf{n}$ & $\%$ & $\mathbf{n}$ & $\%$ & $\mathbf{n}$ & $\%$ & $\mathbf{n}$ & $\%$ & $\mathbf{n}$ & $\%$ \\
\hline \multirow[t]{2}{*}{4} & Laki-laki & 2 & 29 & 12 & 50 & 3 & 11 & - & & - & & 17 & 19 \\
\hline & Perempuan & 5 & 71 & 9 & 38 & - & & - & & - & & 14 & 16 \\
\hline \multirow[t]{2}{*}{5} & Laki-laki & - & & 1 & 4 & 12 & 47 & 3 & 13 & 1 & 11 & 17 & 19 \\
\hline & Perempuan & - & & 2 & 8 & 6 & 23 & 1 & 4 & - & & 9 & 10 \\
\hline \multirow[t]{3}{*}{6} & Laki-laki & - & & - & & 2 & 8 & 10 & 44 & 6 & 67 & 18 & 20 \\
\hline & Perempuan & - & & - & & 3 & 11 & 9 & 39 & 2 & 22 & 14 & 16 \\
\hline & OTAL & 7 & 100 & 24 & 100 & 26 & 100 & 23 & 100 & 9 & 100 & 89 & 100 \\
\hline
\end{tabular}

\section{Tingkat Pengetahuan Sampel}

\section{Sebelum Perlakuan}

Pengetahuan sampel sebelum perlakuan mayoritas berpengetahuan cukup, berada di seluruh kelas $4(16 \%)$ kelas $5(11 \%)$, dan kelas $6(18)$, minoritas berpengetahuan baik yakni di kelas $4(9 \%)$, kelas $5(7 \%)$, kelas $6(8 \%)$, sebagaimana disajikan pada Tabel 2.

Tabel 2. Distribusi Pengetahuan Sebelum Perlakuan

\begin{tabular}{|c|c|c|c|}
\hline \multirow[t]{2}{*}{ kelas } & \multirow[t]{2}{*}{ Pengetahuan } & \multicolumn{2}{|c|}{ Sebelum Perlakuan } \\
\hline & & $\mathbf{n}$ & $\%$ \\
\hline \multirow{3}{*}{4} & Kurang & 9 & 10,0 \\
\hline & Cukup & 14 & 16,0 \\
\hline & Baik & 8 & 9,0 \\
\hline \multirow{3}{*}{5} & Kurang & 10 & 11,0 \\
\hline & Cukup & 10 & 11,0 \\
\hline & Baik & 6 & 7,0 \\
\hline \multirow{4}{*}{6} & Kurang & 9 & 10,0 \\
\hline & Cukup & 16 & 18,0 \\
\hline & Baik & 7 & 8,0 \\
\hline & Jumlah & 89 & 100,0 \\
\hline
\end{tabular}




\section{Sesudah Perlakuan}

Pengetahuan sampel sesudah perlakuan mayoritas berpengetahuan cukup berada di seluruh kelas $4(19 \%)$, kelas $5(16 \%)$, dan kelas $6(11)$, minoritas berpengetahuan kurang yakni di kelas $4(10 \%)$, kelas $5(3 \%)$, kelas $6(8 \%)$, sebagaimana disajikan pada Tabel 3.

Tabel 3. Distribusi Pengetahuan Sampel Sesudah Perlakuan

\begin{tabular}{|c|c|c|c|}
\hline \multirow[t]{2}{*}{$\mathbf{K}$} & \multirow[t]{2}{*}{ Pengetahuan } & \multicolumn{2}{|c|}{ Sesudah Perlakuan } \\
\hline & & $\mathbf{N}$ & $\%$ \\
\hline \multirow{3}{*}{4} & Kurang & 9 & 10,0 \\
\hline & Cukup & 17 & 19,0 \\
\hline & Baik & 5 & 6,0 \\
\hline \multirow{3}{*}{5} & Kurang & 3 & 3,0 \\
\hline & Cukup & 14 & 16,0 \\
\hline & Baik & 9 & 10,0 \\
\hline \multirow{4}{*}{6} & Kurang & 7 & 8,0 \\
\hline & Cukup & 10 & 11,0 \\
\hline & Baik & 15 & 17,0 \\
\hline & Jumlah & 89 & 100,0 \\
\hline
\end{tabular}

\section{Sebelum dan Sesudah Perlakuan}

Tingkat pengetahuan sampel sebelum perlakuan mayoritas berpengetahuan cukup 40 siswa (45\%), dan minoritas berpengetahuan baik 21 siswa (24\%), sesudah diberikan perlakuan mayoritas berpengetahuan cukup 41 siswa (46\%), dan minoritas berpengetahuan kurang 19 siswa (21\%), sebagaimana disajikan di Tabel 4.

Tabel 4. Distribusi Tingkat Pengetahuan Sampel Sebelum dan Sesudah Perlakuan

\begin{tabular}{lccccc}
\hline & \multicolumn{5}{c}{ Perlakuan } \\
\hline & Pengetahuan & \multicolumn{3}{c}{ Sebelum } & Sesudah \\
\cline { 2 - 5 } & n & \% & n & \% \\
\hline Kurang & 28 & 31,0 & 19 & 21,0 \\
Cukup & 40 & 45,0 & 41 & 46,0 \\
Baik & 21 & 24,0 & 29 & 33,0 \\
\hline Jumlah & $\mathbf{8 9}$ & $\mathbf{1 0 0 , 0}$ & $\mathbf{8 9}$ & $\mathbf{1 0 0 , 0}$ \\
\hline
\end{tabular}

\section{Hasil Skoring Tingkat Pengetahuan Sebelum dan Sesudah Perlakuan}

Berdasarkan tingkat pengetahuan sebelum perlakuan diperoleh nilai rata-rata 8,24 dengan standar deviasi 1,679, sesudah perlakuan diperoleh nilai rata-rata tingkat pengetahuan 8,63 dengan standar deviasi 1,569, sebagaimana disajikan di Tabel 5.

Tabel 5. Distribusi Hasil Skoring Tingkat Pengetahuan Sebelum dan Sesudah Perlakuan

\begin{tabular}{lccccc}
\hline Pengetahuan & $\mathbf{n}$ & $\overline{\boldsymbol{x}}$ & SD & Min & Maks \\
\hline Sebelum & 89 & 8,24 & 1,679 & 2 & 11 \\
\hline Sesudah & 89 & 8,63 & 1,569 & 4 & 11 \\
\hline
\end{tabular}

\section{Pengaruh Metode Ceramah Terhadap Tingkat Pengetahuan}

Berdasarkan Tabel 6, diperoleh rata-rata tingkat pengetahuan sebelum perlakuan 8,24, standar deviasi 1,679, sesudah perlakuan terjadi peningkatan pengetahuan dengan rata-rata 8,63, standar deviasi 1,569, mean difference sebesar $-0,11$ yang berarti rata-rata pengetahuan siswa meningkat sebesar 0,11 setelah perlakuan. Hasil uji Wilcoxon signed rank test diperoleh hasil $p=0,107$ sehingga dapat disimpulkan tidak ada pengaruh perlakuan terhadap tingkat pengetahuan, sebagaimana disajikan di Tabel 6 . 
Tabel 6. Distribusi Hasil Uji Wilcoxon Signed Rank Test Pengaruh Perlakuan Terhadap Tingkat Pengetahuan

\begin{tabular}{lcccc}
\hline \multicolumn{1}{c}{ Variabel } & Mean & Mean difference & SD & P value \\
\hline Pengetahuan & & & & \\
Sebelum & 8,24 & & 1,679 & \\
Sesudah & 8,63 & $-0,11$ & 1,569 & 0,107 \\
\hline
\end{tabular}

\section{Pembahasan}

Tingkat Pengetahuan siswa sebelum perlakuan tentang konsumsi buah dan sayur, yang berpengetahuan kurang yaitu sebanyak 28 siswa (31\%), berpengetahuan cukup 40 siswa (45\%) dan berpengetahuan baik 21 siswa (24\%), sesudah perlakuan berpengetahuan kurang menjadi 19 siswa (21\%), berpengetahuan cukup 41 siswa $(46 \%)$ dan berpengetahuan baik menjadi 29 siswa (33\%). Rata-rata materi yang sudah dikuasai sampel ialah manfaat vitamin dan manfaat sayur dan buah, materi yang belum dikuasai sampel rata-rata tentang akibat kekurangan buah dan sayur serta porsi makan buah dan sayur. Hasil skoring menunjukan ratarata pengetahuan sampel sebelum perlakuan 8,24 dan sesudah perlakuan 8,63 meningkat sebesar 0,11 cenderung ada pengaruh perlakuan terhadap tingkat pengetahuan siswa setelah perlakuan. Berbeda dengan hasil statistik menggunakan uji Wilcoxon signed rank disimpulkan tidak ada pengaruh perlakuan terhadap tingkat pengetahuan siswa, hasil ini tidak sejalan dengan Rahayu (2016) yang menyatakan melalui metode ceramah dapat meningkatkan pengetahuan konsumsi buah dan sayur anak sekolah dasar. Dikarenakan materi yang diberikan kepada siswa berbeda-beda setiap harinya, sehingga mengurangi daya ingat siswa tentang materi yang diberikan sebelumnya, serta sulitnya penceramah melihat mana siswa yang sudah memahami materi dan yang belum memahami materi sehingga siswa yang belum memahami materi tidak bisa diberikan materi ulang dan interaksi hanya berpusat pada penceramah karena kurangnya respon anak didik terhadap materi yang diberikan sehingga siswa sulit untuk diajak terlibat langsung dalam penyampaian materi.

\section{Kesimpulan dan Saran}

1. Hasil pengukuran tingkat pengetahuan konsumsi buah dan sayur siswa sebelum perlakuan mayoritas berkategori cukup dan minoritas berkategori baik di Sekolah Dasar Negeri 060841 Medan.

2. Hasil pengukuran tingkat pengetahuan konsumsi buah dan sayur siswa sesudah perlakuan mayoritas berkategori cukup dan minoritas berkategori kurang di Sekolah Dasar Negeri 060841 Medan.

3. Hasil uji statistik tidak ada pengaruh metode ceramah terhadap tingkat pengetahuan konsumsi buah dan sayur siswa Sekolah Dasar Negeri 060841 Medan.

\section{Saran}

Saran kepada pihak sekolah agar memberi pendidikan kepada siswa tentang manfaat konsumsi buah dan sayur di dalam kegiatan ekstrakulikuler, saran kepada peneliti yang lain perlu penambahan alat peraga dalam penelitian menggunakan metode ceramah. 


\section{Referensi}

Almatsier, Sunita. dkk. 2011. Gizi Seimbang Dalam Daur Kehidupan. Jakarta: Gramedia Pustaka Utama

Azadirachta, Fitria, Laras dan Sumarmi, Sri. 2017. Pendidikan Gizi Menggunakan Media Buku Saku Meningkatkan Pengetahuan dan Praktik Konsumsi Sayur dan Buah Pada Siswa Sekolah Dasar. Vol.12(2). 107-115. https://ejournal.unair.ac.id/MGI/article/download/6105/4786

Dalimartha, Setiawan dan Adnan, Felix. 2013. Fakta Ilmiah Buah dan Sayur. Jakarta: Penebar Plus

Enggar, Anggraeni. 2015. Perbedaan pengaruh pelajaran gizi menggunakan media animasi dan ceramah terhadap pengetahuan gizi , sikap dan perilaku konsumsi buah dan sayur pada anak sekolah dasar. https://eprints.uns.ac.id/19391/

Fibrihirzani, Hafsah. 2012. Hubungan Antara Karakteristik Individu, Orang tua dan lingkungan Dengan Konsumsi Buah dan Sayur pada Siswa SDN Beji dan 7 Depok tahun 2012. http://lib.ui.ac.id/file?file=digital/20318462-S-PDFHafsah\%20Fibrihirzani.pdf

Gumilar, Mochamad, Reky. 2017. Pengaruh penyuluhan gizi seimbang terhadap pengtahuan gizi anak sekolah di sekolah dasar islam terpadu darul hikam bandung. http://repository.poltekkesbdg.info/items/show/823

Kementrian Kesehatan. 2014. Pedoman Gizi Seimbang. Jakarta: Kementrian Kesehatan RI

Kementrian Pendidikan, Dapodik (Data pokok pendidikan) tahun 2018 https://Dapo.dikdasmen.kemendikbud.go.id

Khomsan, Ali. 2000. Teknik Pengukuran Pengetahuan Gizi. Bogor: Institut Pertanian Bogor

Lathipuddin, Muhammad. dkk. 2018. Pengetahuan Buah dan Sayur Sebagai Hasil Penyuluhan Gizi Pada Siswa SD yang Mengalami Obesitas di Kota Bandung. Media Pendidikan, $\begin{array}{llll}\text { Gizi dan } & \text { Kuliner. }\end{array}$ http://ejournal.upi.edu/index.php/Boga/article/download/11596/6967

Lesatri, Ayu, Dewi. 2012. Faktor-faktor yang berhubungan dengan perilaku konsumsi buah dan sayur pada siswa SMP Negeri 226 Jakarta Selatan tahun 2012. http://repository.uinjkt.ac.id/dspace/bitstream/123456789/25921/1/ayu\%20dwi\%20lesta ri-fkik.pdf

Linawati, Rista. 2009. Metode ceramah dan trill (latihan) sebagai pemilihan pembelajaran kosakata bahasa china. https://core.ac.uk/download/pdf/12350025.pdf

Rahayu, Agus, Sri. 2016. Tingkat Pengetahun, Sikap, Tindakan Konsumsi Sayur dan Buah Melalui Edukasi Gizi Cooking Class di Sekolah Dasar Islam Terpadu Al Uswah Bangil Pasuruan. http://repository.unair.ac.id/45653/

Sarwono, Jonathan dan Budiono, Herlina. 2012. Statistik Terapan. Jakarta: Gramedia

Sibagariang, Iana, Tresia A. dkk. 2016. Pengaruh Penyuluhan Tentang Sayur dan Buah Dengan Metode Ceramah dan Bermain Tebak Rasa Terhadap Pengetahuan dan Sikap Dalam Konsumsi Sayur dan Buah Pada Siswa SD Negeri 067254 Kecamatan Medan Deli Tahun 2016. https://jurnal.usu.ac.id/index.php/gkre/article/view/20883

Sulaiman, dkk. 2019. Tingkat Pengetahuan siswa tentang fisioterapi di SMK 2 Sibolga kota Sibolga. Jurnal Amaliah. $\quad$ Vol.3(2): http://jurnallp2m.umnaw.ac.id/index.php/AJPKM/article/download/285/249

Susantya, Carissa, Dwilani dan Hassan, Anwar. 2012. Gambaran tentang pengetahuan, sikap, dan praktik dalam konsumsi buah dan sayur pada siswa kelas 4 di SDN 04 Ciangsana Kabupaten Bogor Tahun 2012. http://lib.ui.ac.id/naskahringkas/2015-08/S44145Carissa\%20Dwilani

Purnama, Dyah, Umi. 2018. Pengobatan vitamin K. Solo: Tiga Ananda 
Putra, Windi, Kusuma. 2016. Faktor-faktor yang berhubungan dengan konsumsi buah dan sayur pada anak sekolah dasar. https://lib.unnes.ac.id/26174/1/6411412033.pdf

Putri, Ronasari, Mahaji. dkk. 2017. Gambaran Pengetahuan Sayur Anak Usia 5-12 Tahun di Yayasan Eleos Indonesia Desa Sukodadi Kecamatan Wagir Kabupaten Malang. Jurnal Ilmu Keperawatan. https://jik.ub.ac.id/index.php/jik/article/download/121/150

Waldani, Dina. dkk. 2018. Pengaruh penyuluhan gizi terhadap perilaku kebiasaan sarapan pagi murid SD solok selatan thaun 2016. Jurnal Kesehatan Andalas. http://jurnal.fk.unand.ac.id/index.php/jka/article/download/798/654

Yurni, Adelwais, Febrianti dan Sinaga, Tiurma. 2017. Pengaruh pendidikan gizi terhadap pengetahuan dan praktik membawa bekal menu seimbang anak sekolah dasar. Vol 11(2). Hal 183-190. Media Gizi Indonesia https://ejournal.unair.ac.id/MGI/article/download/5928/4788 